\title{
Effects of Inactivation of the Periaqueductal Gray on Song Production in Testosterone-Treated Male Canaries (Serinus canaria)
}

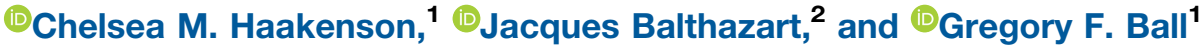

https://doi.org/10.1523/ENEURO.0048-20.2020

${ }^{1}$ Program in Neuroscience and Cognitive Science, Department of Psychology, University of Maryland, College Park, MD 20742, and ${ }^{2}$ Laboratory of Behavioral Neuroendocrinology, GIGA Neurosciences, University of Liege, 15 Avenue Hippocrate, 4000, Liege, Belgium

\section{Visual Abstract}
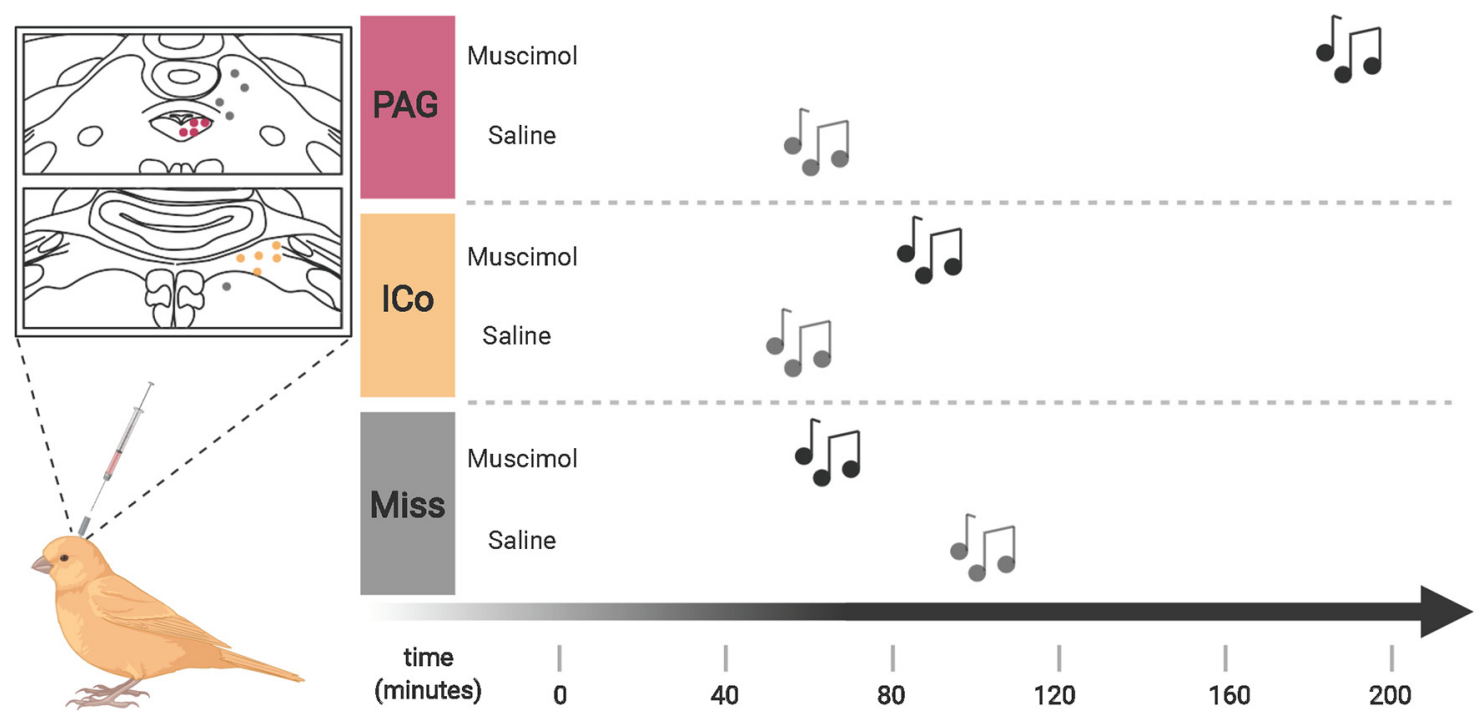

Male canaries (Serinus canaria) display seasonal changes in the motivation to sing which have been found to be dependent on the action of testosterone $(T)$. During the breeding season when $T$ is high, males sing at a higher rate compared with males with low $\mathrm{T}$. The effect of $\mathrm{T}$ on song rate is known to be mediated by the medial preoptic nucleus (POM); however, it is unclear how $\mathrm{T}$ signaling in POM impacts song production. One

\section{Significance Statement}

Communication is essential for social species relying on coordinated behavior for survival and reproduction. However, the neural mechanisms underlying the motivation to engage in vocal communication are currently unknown. Here, we show that inhibition of the periaqueductal gray (PAG) increases the latency for male canaries to sing but does not influence features of song quality once they resume singing. These results indicate that the PAG is involved in regulating the motor initiation or the underlying motivation of the complex, learned behavior of singing but not of innate vocalizations, such as calls. Our findings suggest that the PAG is likely involved in transmitting preoptic signals to the song control system, probably via dopaminergic projections from this region to song control nuclei. 
potential mechanism is via modulation of dopaminergic input into song control nuclei by the periaqueductal gray (PAG). In order to test the role of PAG in T-mediated song production, we treated male canaries with peripheral $T$ implants and implanted a guide cannula targeting the PAG. Through this guide cannula, we transiently inactivated PAG with injections of the $\mathrm{GABA}_{A}$ agonist, muscimol. Each bird received multiple infusions of both muscimol and saline with a 48-h washout period between treatments. The order of injection type was randomized and counterbalanced between individuals. Muscimol infusion into the PAG, but not nearby regions, increased the latency to sing post-injection. These results support the hypothesis that PAG is involved in the production of song, potentially mediating the motivation to sing or alternatively interfering with the premotor activity of nucleus RA. Other song features were however not affected.

Key words: motivation; periaqueductal gray; singing behavior; songbird

\section{Introduction}

For social species, communication between individuals is essential for forming bonds and promoting survival. Without the ability to communicate, the benefits of living in a social group, such as coordinated food gathering, collective defense of self and territory, mating, and caring for young, are unattainable. However, having the ability to communicate verbally is useless if one does not actually do so. Therefore, individuals that live in social groups must be motivated to engage in vocal communication. Currently, the neural circuits and molecular mechanisms underlying this motivation are largely unknown.

Songbirds are an ideal model for addressing this problem, as they rely on vocal communication to relay biologically significant information, and have a vocal learning process with many parallels to that of humans (Doupe and Kuhl, 1999; Kuhl, 2000, 2003; Konishi, 2004). While song can have a variety of functions, one of its key utilities is in mate attraction (Catchpole and Slater, 2008). Appropriately, in seasonally breeding songbird species such as the canary (Serinus canaria), the motivation to sing increases during the breeding season, when attracting a mate is particularly important (Voigt and Leitner, 2008). At this time, males also have increased plasma testosterone (T; Ball et al., 2002; Leitner et al., 2003; Ball and Balthazart, 2017). It is this increase in T that leads to a heightened motivation to sing, in addition to a variety of other effects on song quality (Ball et al., 2003).

This effect of $T$ on the motivation to sing appears to occur via activity in the medial preoptic nucleus (POM),

Received February 11, 2020; accepted July 24, 2020; First published July 31, 2020.

The authors declare no competing financial interests.

Author contributions: C.M.H., J.B., and G.F.B. designed research; C.M.H. performed research; C.M.H. analyzed data; C.M.H., J.B., and G.F.B. wrote the paper.

This work was supported by the National Institute of Neurological Disorders and Stroke Grant 1 R01 NS104008-01. C.M.H. was supported, in part, by the National Science Foundation Award DGE-1632976.

Acknowledgements: We thank Nikolai Smith and Dr. Edward Smith for designing and printing the custom beak bar used for the surgeries and Zewde Ingram, Devanshi Kanani, Sydney Gittelman, and Afina Karapetyan for assistance quantifying song quality measures and call rate.

Correspondence should be addressed to Chelsea M. Haakenson at chaakens@umd.edu.

https://doi.org/10.1523/ENEURO.0048-20.2020

Copyright (C) 2020 Haakenson et al.

This is an open-access article distributed under the terms of the Creative Commons Attribution 4.0 International license, which permits unrestricted use, distribution and reproduction in any medium provided that the original work is properly attributed. since implantation of $\mathrm{T}$ specifically in this region in castrated male canaries increases the number of songs per minute and the percentage of time spent singing (Alward et al., 2013). In addition, partially lesioning the POM has the inverse effect, causing male European starlings (Sturnus vulgaris) to sing less frequently (Riters and Ball, 1999; Alger et al., 2009). However, it is not yet known how $\mathrm{T}$ in POM can induce such changes in song behavior.

One potential pathway for transmission of T-modulated activity in POM to the song control system is via the periaqueductal gray (PAG). There are reciprocal projections between PAG and POM (Riters and Alger, 2004). In addition, PAG sends dopaminergic projections to several nuclei in the song control system, HVC, the robust nucleus of the arcopallium (RA), and area X (Lewis et al., 1981; Appeltants et al., 2000, 2002; Castelino et al., 2007). Neural activity in PAG also appears to be tied to activity in POM, as European starlings with lesions to POM have decreased expression of the immediate early gene ZENK in the PAG (Alger et al., 2009). Furthermore, DOPAC, a metabolite of dopamine, in PAG has been found to correlate with song production (Heimovics et al., 2011).

In the present study, we examine the role of PAG in the control of singing. We castrated male canaries and implanted them with SILASTIC implants that continuously release $\mathrm{T}$, ensuring high singing rates. We then implanted guide cannulas to target the PAG for neurochemical manipulation in these males. We conducted six trials per individual, alternating infusion of saline (vehicle) or the $G_{A B A}$ agonist muscimol into this brain region. We hypothesized that PAG transmits to the song system T-modulated activity from POM and accordingly sends motivational cues to song control nuclei. Therefore, we predicted that during trials in which PAG was transiently inactivated, males would either refrain from singing for some time following infusion or sing less frequently than in control trials. Furthermore, we predicted that this effect would be limited to song, since Tmodulated changes in vocal behavior are limited to song, which is learned, and do not affect calls, which are innate.

\section{Materials and Methods}

All animal procedures were performed in accordance with the University of Maryland, College Park animal care committee's regulations.

\section{Experimental animals and pre-experimental manipulations}

Fourteen adult male canaries ( $S$. canaria) of the American Singer strain were obtained from a local breeder 
(Maryland Exotic Birds). Upon arrival, birds were housed in grouped aviaries on a short-day photoperiod (8/16 h light/dark; 8L:16D) to induce photosensitivity (Nicholls and Storey, 1977). All animals were provided with ad libitum food and water. Male birds were castrated under anesthesia (Forane isoflurane, Baxter; Isotex four anesthesia machine, Surgivet) through an incision between the last two ribs on each side. Birds were allowed to recover in their home cage for six weeks to allow adequate time for any residual physiological or behavioral effects of endogenous $T$ to clear.

\section{Stereotaxic implantation}

Birds were anesthetized using isoflurane gas and placed in a stereotaxic apparatus modified for use in small birds. Beaks were placed in a custom, 3D-printed beak holder placed at $45^{\circ}$ below the horizontal axis of the apparatus. Each bird received a unilateral guide cannula (26 gauge, C315GMNSPC, Plastics One) implant targeting PAG. In order to target PAG without puncturing the ventricle and inducing bleeding, we oriented the stereotaxic arm at a $40^{\circ}$ angle to the right from vertical and then used the following stereotaxic coordinates: dorsoventral: $-7.1 \mathrm{~mm}$ from the dorsal surface of the brain; anteriorposterior: $0 \mathrm{~mm}$ from the most rostral tip of the cerebellum; medial-lateral: $4.5 \mathrm{~mm}$ to the right from midline. The cannula was lowered to the target coordinates, and dental cement was applied around the implant. The skin was sutured around the implant. At the time of stereotaxic surgery, males were also implanted subcutaneously with a 12-mm-long SILASTIC implant (Dow Corning; internal diameter, $0.76 \mathrm{~mm}$; external diameter, $1.65 \mathrm{~mm}$ ) packed with $10 \mathrm{~mm}$ of $\mathrm{T}$ to standardize circulating $\mathrm{T}$ levels. Following recovery from surgery, males were transferred to individual sound-attenuating chambers $(41 \times 48 \times$ $51 \mathrm{~cm}$ ) set to $14 \mathrm{~L}: 10 \mathrm{D}$ to simulate breeding photoperiods.

\section{Microinfusion procedures}

In the week following surgery, birds were handled daily and the dummy injectors were removed and reattached so that the birds would habituate to experimental manipulations. After a male had been observed to sing at least 2 $d$ in a row, he underwent a mock infusion session to acclimate him to the infusion procedure, in which saline was infused through the internal cannula in the same protocol as later test infusions. Test infusions began $2 \mathrm{~d}$ after the acclimation infusion. Each bird underwent six experimental infusion sessions: three sessions with $0.2 \mu \mathrm{l} 0.9 \%$ saline (vehicle) and three sessions with muscimol in $0.9 \%$ saline $(0.5 \mu \mathrm{g} / 0.2 \mu \mathrm{l}$ solution, catalog \#0289, Tocris). Infusions alternated between vehicle and drug, but the starting infusion type was randomized and counterbalanced across individuals. Infusion sessions were separated by at least $48 \mathrm{~h}$ to allow for drug washout. During infusions, the dummy injector was replaced by an internal cannula (33 gauge, C315IMNSPC, Plastics One) connected to a Hamilton microliter syringe via a polyethylene tube. The syringe was loaded into a syringe pump (KDS 220, KD Scientific) programmed to deliver treatment (vehicle or drug) at a rate of $0.1 \mu \mathrm{l} / \mathrm{min}$ for $2 \mathrm{~min}$, for a total volume of $0.2 \mu \mathrm{l}$. Following infusion, the internal cannula was held in place for an additional minute to allow for diffusion and to avoid reflux of the solution. Birds were then returned to their home chamber. Chambers contained a combination microphone/camera (Mini Spy HD 1000TVL, TPEKKA) connected to a computer running DVRserver (V6.33b; Mammoth Technologies) designed for real-time video and audio surveillance. Video and audio were recorded for the remainder of the day following infusions.

\section{Behavior quantification}

Videos for each day were downloaded and converted into two filetypes: AVI files for video viewing and WAV files for audio analysis. In order to quantify the latency to sing, we used two independent measures. First, videos were watched from the time a bird was returned to the chamber after drug infusion until the bird was observed singing. The difference in time between infusion and singing was recorded. Audio files were independently inspected in Adobe Audition, and the time between the sound of the bird being returned to the chamber and the start of singing was recorded. These two measures were then compared with ensure that the recorded latency to sing was accurate. In two instances where there were differences between the latency recorded from videos or from audio files, another investigator analyzed the corresponding files to determine which measure was correct and ultimately a consensus was reached on the true time when the first song occurred. For measures of song quality, we used Audition to clip audio files to be $1 \mathrm{~h}$ in length, starting at the bird's first song post-infusion. These files were analyzed using Avisoft (SASlab Pro). Songs were defined as bouts of vocalizations longer than or equal to $1 \mathrm{~s}$ in duration and separated by $500 \mathrm{~ms}$ of silence (Alward et al., 2013). One bird was excluded from any analysis of song quality, because of high background noise from the chamber fan. In order to measure the number of calls, experimenters watched video recordings of the hour following return to the chamber following infusions. For each minute of the hour, experimenters counted the number of calls that occurred during that minute, and all counts were summed at the end to get the number of calls that occurred during the entire hour. The same procedure was used to quantify perch hops, as a measure of general activity following infusion, for 20 min of video following return to the chamber. For all behavior quantification procedures, experimenters were blind to treatment and cannula placement.

\section{Verification of cannula targets}

After birds completed all six test microinfusion sessions, we performed a final microinfusion of $0.2-\mu$ fluorescent-conjugated muscimol (Muscimol BODIPY TMR-X Conjugate, catalog \#M23400, ThermoFisher) according to the procedure described above. We allowed $30 \mathrm{~min}$ for muscimol diffusion before extracting brains and flash freezing them on dry ice. Brains were stored at $-80^{\circ} \mathrm{C}$. Brain tissue was sectioned with a cryostat (Microm HM 
A

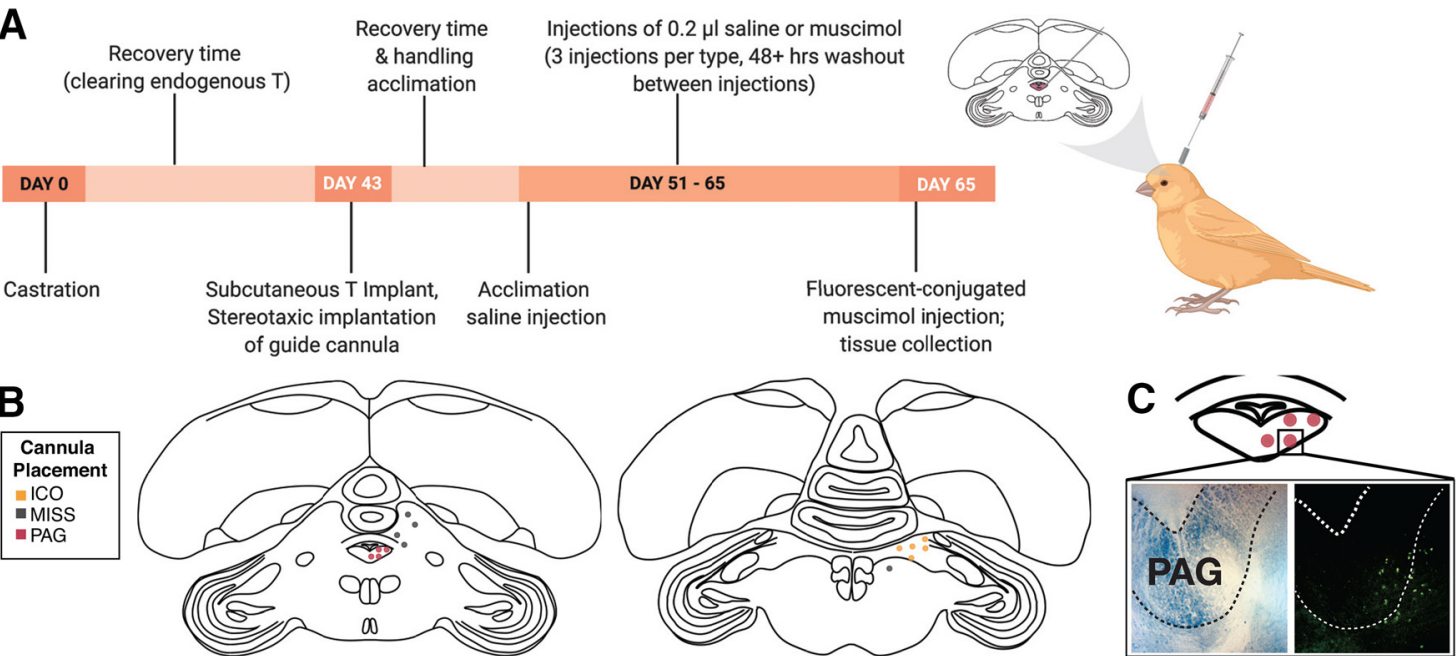

Figure 1. Experimental procedures. A, Timeline of experimental procedures (left) and image of cannula trajectory (right) created with BioRender. B, Coronal sections demonstrating final placement of cannula targets after surgery, four in PAG, five in ICo, and five misses. C, Example images of muscimol spread for an individual where cannula placement was on the lateral edge of PAG. Left is a Nissl brightfield photomicrograph showing the location of PAG and right is the corresponding fluorescent photomicrograph.

$500 \mathrm{OM})$ at $50 \mu \mathrm{m}$ in the coronal plane and directly mounted on slides. We then visualized the spread of fluorescent muscimol and the location of tracts created by the guide cannula to determine whether the cannula was accurately targeting PAG for drug infusion.

\section{Data analysis}

We analyzed latency, song measures, and call data using repeated-measures ANOVA, with cannula placement and treatment (muscimol, saline) as factors. In addition, we performed estimation based on confidence intervals (Cls) using the Data Analysis using BootstrapCoupled Estimation (dabestr) package, written for use in the $\mathrm{R}$ programming language (Ho et al., 2019). For song measures, which encompassed singing behavior in the hour after the bird began singing, we combined data from multiple songs to create a single value for each acoustic feature, averaged across all vocalizations in the hour of audio quantified for each individual and trial. Total number of songs was calculated by adding the number of vocalizations that met our criteria for song. Time spent singing was calculated by adding the duration of each of these songs. For measures that concerned each individual song (song duration, interval between songs, number of song elements, energy, peak to peak amplitude, root mean square (RMS) amplitude, entropy, fundamental frequency, bandwidth, peak amplitude, and peak frequency), we averaged the values of each measure across the songs sung within the 1-h song file for a given trial. These measures were chosen to quantify a range of song features including stereotypy, volume, and frequency range.

\section{Results}

Because of variation in accuracy of stereotaxic implantation of guide cannulas, subjects were categorized in three groups based on the location: PAG, intercollicular nucleus (ICo), and misses (Fig. 1). Five males were categorized in the ICo group, five in the miss group, and four in the PAG group. The fluorescent muscimol spread an average of $533 \mu \mathrm{m}$ in the ventral-medial direction away from the end of the guide cannula tract and an average of

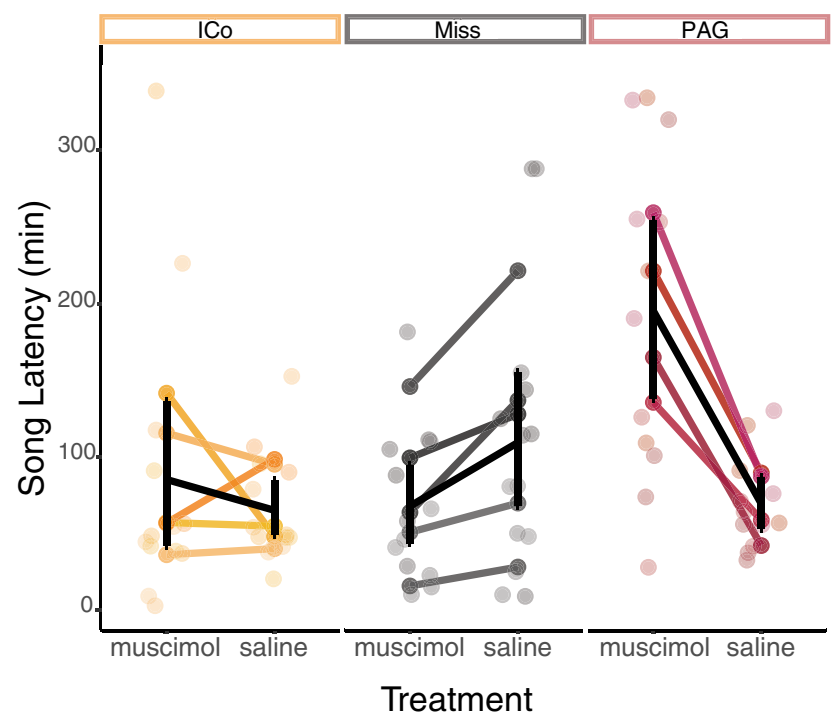

Figure 2. Change in latency to begin singing post-infusion. Differences in latency for each individual across trial type. Each line connects the average latency to sing following muscimol infusion to the average latency following saline infusion for an individual bird. Black lines indicate summary statistics (mean and SEM), while colored lines indicate the average latency for each individual bird. Individual points indicate the latency for each single trial. The three sections of the graph represent cannula placement (ICo, miss, or PAG). In order to determine whether an ANOVA was appropriate to determine differences between treatments, we tested the assumption of homoscedasticity (Extended Data Fig. 2-1A). To further assess the differences between groups and treatments, we used bootstrapped estimation statistics of $95 \%$ Cls (Extended Data Fig. 2-1B). 


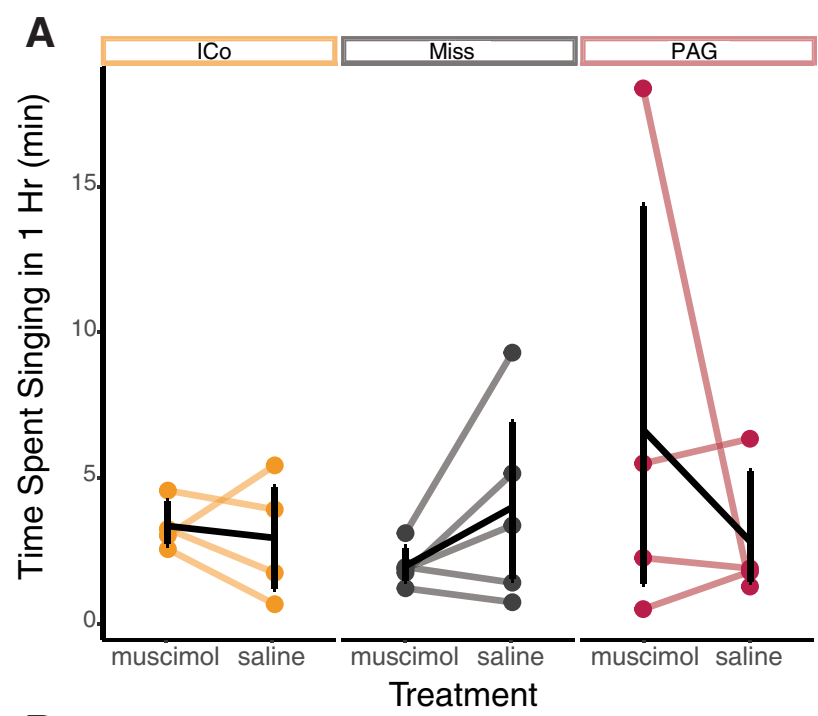

B
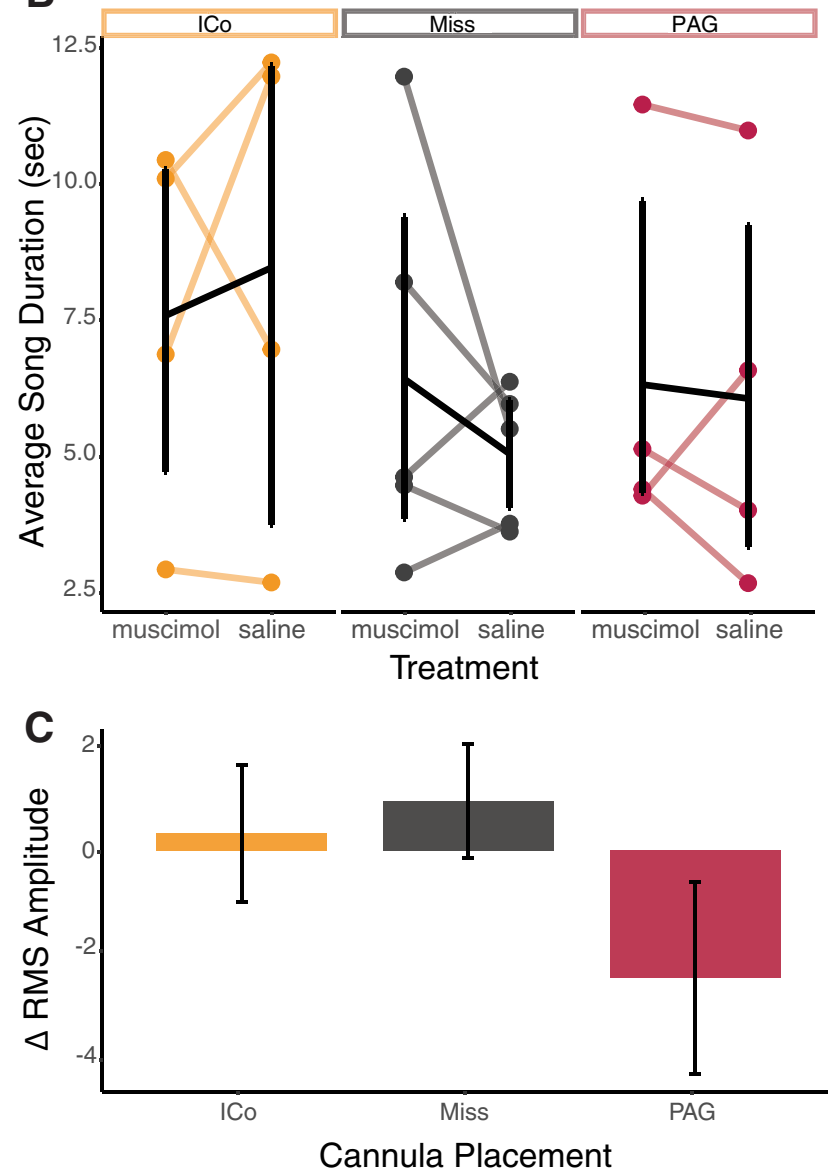

Figure 3. Example song quality measurements. $\boldsymbol{A}$, The amount of time in minutes spent singing $1 \mathrm{~h}$ after singing began. There were no significant differences between treatments or cannula placement. The three sections of the graph represent cannula placement (ICo, miss, or PAG). B, The average duration of songs in seconds. There were no significant differences between treatments or cannula placement. $\boldsymbol{C}$, Average change in RMS amplitude between treatments (muscimol minus saline). There was a significant interaction between treatment and cannula placement but no main effect. Each line connects the
$225 \mu \mathrm{m}$ in the perpendicular direction. In individuals where the guide cannulas targeted PAG, this spread was sufficient to cover at least some portion of the contralateral side, in addition to affecting the hemisphere containing the guide cannula. When guide cannulas targeted regions that are located more laterally (ICo and misses), this spread only affected the hemisphere ipsilateral to the guide cannula. To determine whether muscimol diffused into the aqueduct and was transported to other brain regions via the ventricular system, we assessed fluorescence around the aqueduct and across brain regions in the telencephalon and diencephalon. We did not observe fluorescence above standard autofluorescence in any brain regions outside the mesencephalon near cannula tracts.

\section{Song latency}

There was a significant difference in latency to begin singing between muscimol and saline trials $\left(F_{(1,11)}=5.775\right.$, $\left.p=0.035, \eta^{2}=0.046\right)$ and a significant interaction between cannula placement and treatment $\left(F_{(2,11)}=19.222, p<\right.$ $0.001, \eta^{2}=0.303$; Fig. 2). There was no significant main effect of cannula placement alone on latency to $\operatorname{sing}\left(F_{(2,11)}=\right.$ 1.873, $p=0.200, \eta^{2}=0.143$ ). The effect of treatment was driven by differences in the group with guide cannulas targeting PAG. In birds with cannulas targeting PAG, there was a large increase in time to sing post-infusion for muscimol trials compared with saline trials [mean muscimol latency minus saline latency $(\Delta \mathrm{L})=125.75 \mathrm{~min}, \mathrm{SE}=13.50$ ], while differences in latency in birds with cannula targeting ICo $(\Delta \mathrm{L}=20.10 \mathrm{~min}, \mathrm{SE}=14.34)$ and in birds with cannula targets classified as misses $(\Delta \mathrm{L}=-41.50 \mathrm{~min}, \mathrm{SE}=20.43)$ were smaller. We found a similar pattern of results by performing estimation statistics with the dabestr $\mathrm{R}$ package. We created 5000 bootstrapped sample distributions representing the difference in latency to sing for muscimol trials minus saline trials, such that a positive estimation would indicate a larger latency to sing following muscimol infusions compared with saline infusions. The PAG group had a 95\% $\mathrm{Cl}$ that indicated a larger latency to sing following muscimol trials compared with saline trials $(126 \mathrm{~min}, 95 \% \mathrm{Cl}[71.8$; 184]). The $95 \% \mathrm{Cl}$ for the ICo group (28 min, $95 \% \mathrm{Cl}$ $[-3.21 ; 113])$ included 0 , indicating that there is likely no difference in latency to sing between muscimol and saline trials. The Miss group's $95 \% \mathrm{Cl}(-38.8 \mathrm{~min}, 95 \% \mathrm{Cl}[-99.5$; -9.51]) was close to zero, but did not include zero, indicating a small increase in latency to sing for saline trials.

\section{Song measures}

In the hour after birds began singing, we did not find any significant differences between treatments (saline or muscimol) or between cannula placements for the amount of time spent singing (total number of songs, total amount of time spent singing) or measures of song quality (song

\section{continued}

average data following muscimol infusion to the average data following saline infusion. Black lines indicate summary statistics (mean and SEM), while colored lines indicate the average data for each individual bird. 
Table 1: Results of two-way repeated measures ANOVA of song quality measures

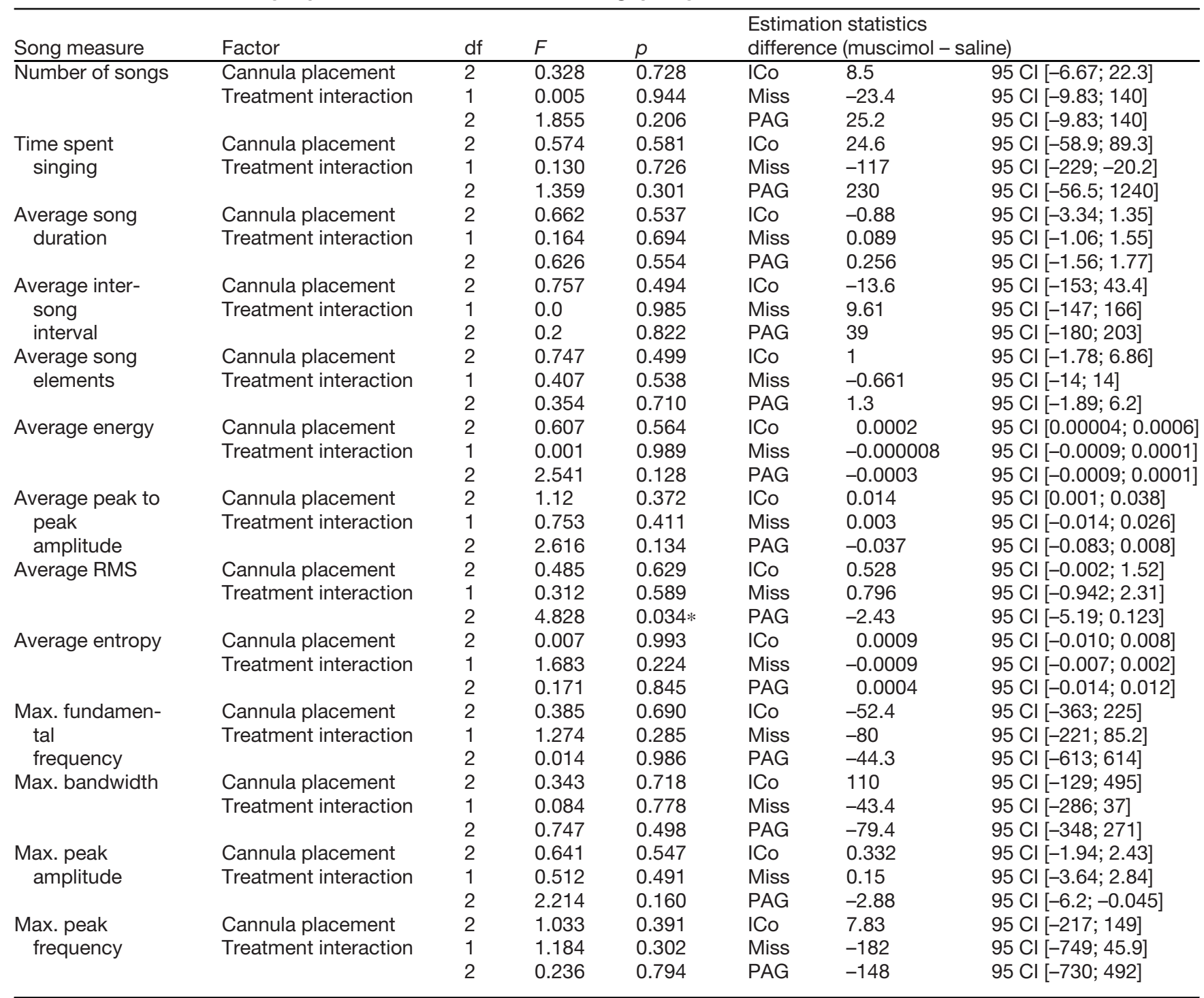

duration, interval between songs, energy, number of elements, peak to peak frequency, fundamental frequency, entropy, bandwidth, or amplitude; Fig. 3; for results of statistical analyses, see Table 1). We did observe a significant interaction between treatment and placement for RMS amplitude $\left(F_{(2,10)}=4.828, p=0.0341\right)$. However, the lack of significant main effects of cannula placement $\left(F_{(2,10)}=0.485\right.$, $p=0.629)$ or treatment $\left(F_{(1,10)}=0.312, p=0.589\right)$ and the small effect size $\left(\eta^{2}=0.012\right)$ suggests that this may be a spurious effect. Furthermore, the $95 \% \mathrm{Cl}$ of bootstrapped differences between muscimol and saline trials included zero in all groups, supporting the idea that this is not a real effect (PAG: -2.43 RMS power, 95\% Cl [-5.19; 0.123]; ICo: 0.528 RMS power, 95\% Cl [-0.002; 1.52]; Miss: 0.796 RMS power, 95\% Cl [-0.942; 2.31]).

\section{Calls}

We also quantified the number of calls birds made in the hour immediately following infusion and found no significant differences between treatments $\left(F_{(1,11)}=4.783\right.$, $p=0.054)$, cannula placements $\left(F_{(2,11)}=0.468, p=0.639\right)$, or an interaction between the two $\left(F_{(2,11)}=2.549, p=\right.$ 0.127; Fig. 4). Likewise, 95\% Cls of the difference between muscimol and saline trials included zero for all three cannula placements (PAG: -53.9 calls, 95\% Cl [-140; 0.75], ICo: -24.3 calls, 95\% Cl [-92.3;53], Miss: 4.31 calls, $95 \% \mathrm{Cl}[-18.2 ; 44.2])$.

\section{General activity}

We did not find a difference in the number of perch hops following infusion between cannula placements $\left(F_{(2,11)}=0.546, p=0.594\right)$, between saline and muscimol trials $\left(F_{(1,11)}=0.228, p=0.643\right)$, or an interaction between placement and treatment for any cannula placement. $\left(F_{(2,11)}=0.942, p=0.419\right)$. Likewise, the $95 \%$ Cls of difference between muscimol and saline trials included zero for all conditions (PAG: -19.3 perch hops, $95 \mathrm{Cl}$ [-68.9; 0.1], ICo: -5.6 perch hops, $95 \mathrm{Cl}[-27.1 ; 3.4]$, miss: 11.3 perch hops, $95 \mathrm{Cl}[-8.27 ; 37.2])$. 


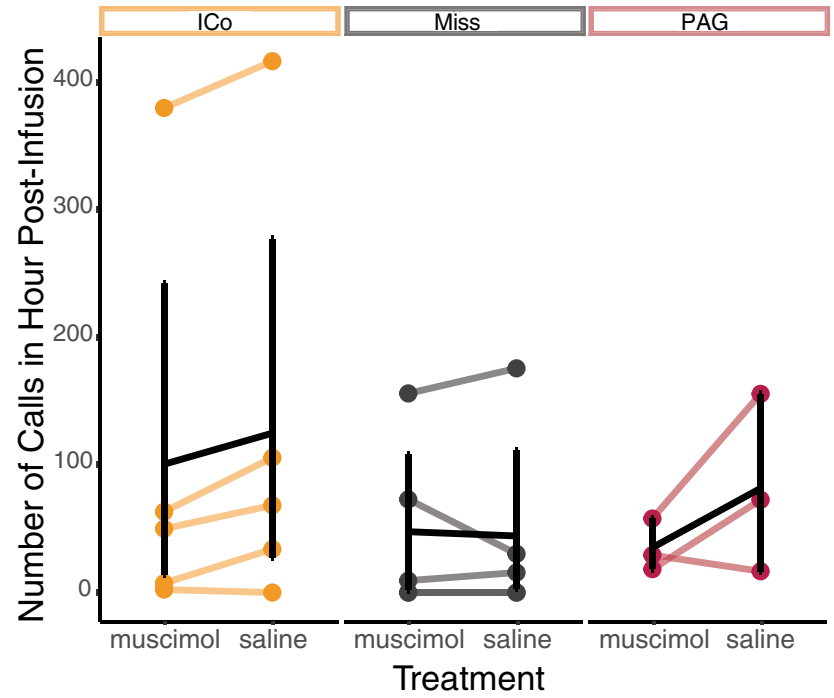

Figure 4. There were no significant differences in call rate in the hour following infusion. Difference between muscimol and saline trials (average number of calls following muscimol infusion minus average number of calls following saline infusion) for individual birds. Colors represent cannula placement. Each line connects the average call rate following muscimol infusion to the average call rate following saline infusion. Black lines indicate summary statistics (mean and SEM), while colored lines indicate the average data for each individual bird.

\section{Discussion}

This study found that transiently inactivating the PAG increases the latency to sing in castrated male canaries treated with exogenous $\mathrm{T}$. Since muscimol infusion into this region increased the latency to sing, while having no effect on other aspects of song production, PAG seems to be specifically involved in the initiation of singing behavior. This could be because of PAG conveying cues from the POM to the song control system. The interpretation of these results depends critically on the assumed duration of muscimol infused into the PAG. Based on past pharmacological studies, it is likely that the dose of $0.5-\mu \mathrm{g}$ muscimol we infused in the PAG activated $\mathrm{GABA}_{\mathrm{A}}$ receptors for a duration of one or $2 \mathrm{~h}$. Indeed a previous study found that an intraperitoneal injection of muscimol produced an analgesia in the hot plate test that was fully effective for $40 \mathrm{~min}$ and was already decreasing at $60 \mathrm{~min}$, with an extrapolated return to baseline before $2 \mathrm{~h}$ after injection (Sawynok and Labella, 1982). Using an approach more similar to the present work, muscimol infused into the preoptic area decreased the lordosis quotient of female rats at 10 and, to a lower extent, 30 min after infusion, but the behavior returned to baseline at $60 \mathrm{~min}$. A similar time course was observed for the stimulation of lordosis by muscimol injected into the medial hypothalamus (McCarthy et al., 1990). These durations of action depend on the doses that are injected but studies combining doses and duration are rare and, to our knowledge, do not exist for brain injections. Based on these data, it seems likely that our injections of a low dose of muscimol modulated $\mathrm{GABA}_{\mathrm{A}}$ activity for a duration of about $1-2 \mathrm{~h}$, which explains why singing activity resumed
125 min later but the quality of the songs produced at that time was not affected. If $\mathrm{GABA}_{A}$ activity was still increased when singing activity recovered, this would mean that PAG does not control song quality, since song was normal at that time. However, we do not believe that this interpretation is very likely, because it would then be difficult to understand why singing activity recovered.

In mammalian species, electrical stimulation of the PAG has been shown to elicit innate, species-specific calls (Jürgens, 1994). However, little is known concerning the function of PAG in regulating learned vocalizations, such as song. Projections from the PAG to HVC have been found to be important during zebra finch (Taeniopygia guttata) development and song learning, allowing juveniles to detect the presence of a tutor and encode the tutor song (Tanaka et al., 2018). Our results indicate that the medial PAG has additional influence on adult song, presumably by transmitting signals from POM to the song system.

The nature of the information transferred from POM to PAG would however require additional investigations. In canaries, we have collected extensive evidence indicating that $\mathrm{T}$ action in the POM is necessary for singing behavior to occur but does not modify song quality (Riters and Ball, 1999; Alger and Riters, 2006; Alger et al., 2009; Alward et al., 2013, 2016a,b; Vandries et al., 2019). We have therefore hypothesized that the POM modulates the motivation to sing, but it could also be postulated that these effects reflect a modulation of the motor aspects of singing. It is challenging to distinguish between these two hypotheses. The term motor control is usually used for mechanisms that are relatively close to the effector muscles, including for example the motor magnocellular neurons directly projecting to the spinal chord or possibly neurons in the PAG. The preoptic area is rather considered as an integration area that modulates higher order processes, including motivation. It is often assumed in the literature on male sex behavior in rodents that an increased latency to show sexual behavior after introduction of a female reflects a decrease in motivation (Melis and Argiolas, 1995), and we think that the delay in singing initiation reflects here a similar mechanism. The interpretation of the present experiments is thus probably not that inactivating PAG directly blocks a motor transmission to the muscles of the syrinx (such a direct projection is not known to exist) but rather that this inactivation interrupts transmission of a "motivational" signal from POM to HVC and/or RA. It is however true that RA is myotopically organized based on the muscles of the syrinx (Vicario, 1991) so an indirect modulation of the motor control of the syrinx via the PAG projection to RA could potentially contribute to the effects we have observed in this study.

The observation that the general activity of the birds (i.e., perch hopping) and the rate of calling behavior were not affected by muscimol during the period when song was inhibited supports the specificity of the effect on song and argues against an interpretation that would be based on a general inhibition of activity or on a non-specific stress response. However, given the difficulties of ascribing a strictly motivational role to the observed effect of transiently inactivating PAG, additional data would be 
required to completely dissociate this region's effects on motivation as compared with the motor control of the syrinx.

Notably, it appears that the medial PAG, and not ICo, regulates these motivational signals. Birds with cannulas targeting this region took an average of 125 min longer to begin singing after muscimol infusions, presumably refraining from singing until the muscimol wore off, while birds with cannulas targeting other regions did not display a large difference in song latency between muscimol and saline trials. Immunohistochemical analysis has indicated that this region, referred to as the mesencephalic central gray in some older publications (Stokes et al., 1974), is organized like a folded open ventral mammalian PAG, while the laterally adjacent ICo appears to be homologous to the dorsal mammalian PAG (Kingsbury et al., 2011). In addition, the medial PAG contains the A11 group of catecholaminergic neurons, sending projections to the song control system (Appeltants et al., 2000, 2002). We hypothesize that the motivational cues from the POM are transmitted to the song system via these projections. Future studies should investigate these catecholaminergic inputs into song control nuclei and their influence on song behavior.

These results indicate that PAG is involved in the initiation of singing behavior and may regulate the motivation to produce song, but cannulas misplaced in the ICo served as a valuable control as ICo has been implicated in production of innate calls (Popa and Popa, 1933; Nieder and Mooney, 2020). Because of this literature, we expected a decrease in calling behavior following muscimol infusion into this region. However, we did not observe such a difference, likely due the placement of cannula. For cannulas targeting PAG, the medial position of the nucleus allowed muscimol to spread and to affect the bilateral extent of the structure. In contrast, when the cannula was located in ICo, a nucleus located more laterally, muscimol was not able to spread to the contralateral side to induce bilateral inactivation. Bilateral lesions of ICo decrease ring dove (Streptopelia risoria) nest coos, but only unilateral activation of this area with steroid hormones is required to induce an increase in nest-cooing behavior (Cohen and Cheng, 1981, 1982). Therefore, it is possible that using two cannulas to bilaterally inactivate this region would reduce calling behavior, a hypothesis that could be tested in future experiments. In addition, the cannulas classified as being in ICo in this study targeted the medial, rather than lateral, portion of ICo. Since many of the electrical stimulation studies implicating $\mathrm{ICo}$ as a regulator of calling behavior targeted the lateral region of the nucleus close to the dorsomedial nucleus of ICo (DM), it is more likely that this lateral portion is responsible for innate vocalizations (Seller, 1980). Therefore, targeting muscimol treatment in this lateral portion of ICo may potentially result in an inhibition of calling behavior.

Now that PAG has been identified as a region essential for the initiation of song, and potentially controlling the motivation to produce learned vocalizations, future research is required to identify the underlying cellular and molecular mechanisms. Systematically exploring how this region interacts with the song control system and the POM will advance our understanding of the biological underpinnings of social communication.

\section{References}

Alger SJ, Riters LV (2006) Lesions to the medial preoptic nucleus differentially affect singing and nest box-directed behaviors within and outside of the breeding season in European starlings (Sturnus vulgaris). Behav Neurosci 120:1326-1336.

Alger SJ, Maasch SN, Riters LV (2009) Lesions to the medial preoptic nucleus affect immediate early gene immunolabeling in brain regions involved in song control and social behavior in male European starlings. Eur J Neurosci 29:970-982.

Alward BA, Balthazart J, Ball GF (2013) Differential effects of global versus local testosterone on singing behavior and its underlying neural substrate. Proc Natl Acad Sci USA 110:19573-19578.

Alward BA, De Bournonville C, Chan TT, Balthazart J, Cornil CA, Ball GF (2016a) Aromatase inhibition rapidly affects in a reversible manner distinct features of birdsong. Sci Rep 6:32344.

Alward BA, Madison FN, Parker SE, Balthazart J, Ball GF (2016b) Pleiotropic control by testosterone of a learned vocal behavior and its underlying. eNeuro 3:ENEURO.0145-15.2016.

Appeltants D, Absil P, Balthazart J, Ball GF (2000) Identification of the origin of catecholaminergic inputs to $\mathrm{HVc}$ in canaries by retrograde tract tracing combined with tyrosine hydroxylase immunocytochemistry. J Chem Neuroanat 18:117-133.

Appeltants D, Ball GF, Balthazart J (2002) The origin of catecholaminergic inputs to the song control nucleus $R A$ in canaries. Neuroreport 13:649-653.

Ball GF, Balthazart J (2017) Neuroendocrine regulation of reproductive behavior in birds. In: Hormones, brain, and behavior (Pfaff DW, Joëls M, eds), Ed 3, pp 2217-254. Oxford: Academic Press.

Ball GF, Riters LV, Balthazart J (2002) Neuroendocrinology of song behavior and avian brain plasticity: multiple sites of action of sex steroid hormones. Front Neuroendocrinol 23:137-178.

Ball GF, Castelino CB, Maney DL, Appeltants D, Balthazart J (2003) The activation of birdsong by testosterone: multiple sites of action and role of ascending catecholamine projections. Ann NY Acad Sci 1007:211-231.

Castelino CB, Diekamp B, Ball GF (2007) Noradrenergic projections to the song control nucleus area $X$ of the medial striatum in male zebra finches (Taeniopygia guttata). J Comp Neurol 502:544-562.

Catchpole CK, Slater PJB (2008) Bird song: biological themes and variations, Ed 2. New York: Cambridge University Press.

Cohen J, Cheng MF (1981) The role of the midbrain in courtship behavior of the female ring dove (Streptopelia risoria): evidence from radiofrequency lesion and hormone implant studies. Brain Res 207:279-301.

Cohen J, Cheng MF (1982) Effects of testosterone metabolites and estrogen in the midbrain control of courtship behavior in the male ring dove (Streptopelia risoria). Neuroendocrinology 34:64-74.

Doupe AJ, Kuhl PK (1999) Birdsong and human speech: common themes and mechanisms. Annu Rev Neurosci 22:567-631.

Heimovics SA, Salvante KG, Sockman KW, Riters LV (2011) Individual differences in the motivation to communicate relate to levels of midbrain and striatal catecholamine markers in male European starlings. Horm Behav 60:529-539.

Ho J, Tumkaya T, Aryal S, Choi H, Claridge-Chang A (2019) Moving beyond $P$ values: data analysis with estimation graphics. Nat Methods 16:565-566.

Jürgens U (1994) The role of the periaqueductal grey in vocal behaviour. Behav Brain Res 62:107-117.

Kingsbury MA, Kelly AM, Schrock SE, Goodson JL (2011) Mammallike organization of the avian midbrain central gray and a reappraisal of the intercollicular nucleus. PLoS One 6:e20720.

Konishi M (2004) The role of auditory feedback in birdsong. Ann NY Acad Sci 1016:463-475. 
Kuhl PK (2000) A new view of language acquisition. Proc Natl Acad Sci USA 97:11850-11857.

Kuhl PK (2003) Human speech and birdsong: communication and the social brain. Proc Natl Acad Sci USA 100:9645-9646.

Leitner S, Van't Hof TJ, Gahr M (2003) Flexible reproduction in wild canaries is independent of photoperiod. Gen Comp Endocrinol 130:102-108.

Lewis JW, Ryan SM, Arnold AP, Butcher LL (1981) Evidence for a catecholaminergic projection to area $\mathrm{X}$ in the zebra finch. J Comp Neurol 196:347-354.

McCarthy MM, Malik KF, Feder HH (1990) Increased GABAergic transmission in medial hypothalamus facilitates lordosis but has the opposite effect in preoptic area. Brain Res 507:40-44.

Melis MR, Argiolas A (1995) Dopamine and sexual behavior. Neurosci Biobehav Rev 19:19-38.

Nicholls TJ, Storey CR (1977) The effect of duration of the daily photoperiod on recovery of photosensitivity in photorefractory canaries (Serinus canarius). Gen Comp Endocrinol 31:72-74.

Nieder A, Mooney R (2020) The neurobiology of innate, volitional and learned vocalizations in mammals and birds. Philos Trans $R$ Soc Lond B Biol Sci 375:20190054.

Popa GT, Popa FG (1933) Certain functions of the midbrain in pigeons. Proc R Soc B Biol Sci 113:191-195.

Riters LV, Ball GF (1999) Lesions to the medial preoptic area affect singing in the male European starling (Sturnus vulgaris). Horm Behav 36:276-286.
Riters LV, Alger SJ (2004) Neuroanatomical evidence for indirect connections between the medial preoptic nucleus and the song control system: possible neural substrates for sexually motivated song. Cell Tissue Res 316:35-44.

Sawynok J, Labella FS (1982) On the involvement of GABA in the analgesia produced by baclofen, muscimol, and morphine. Neuropharmacology 21:397-403.

Seller TJ (1980) Midbrain regions involved in call production in Java sparrows. Behav Brain Res 1:257-265.

Stokes TM, Leonard CM, Nottebohm F (1974) The telencephalon, diencephalon, and mesencephalon of the canary, Serinus canaria, in stereotaxic coordinates. J Comp Neurol 156:337-374.

Tanaka M, Sun F, Li Y, Mooney R (2018) A mesocortical dopamine circuit enables the cultural transmission of vocal behaviour. Nature 563:117-120.

Vandries LM, Ghorbanpoor S, Cornez G, Shevchouk O, Ball GF, Cornil CA, Balthazart J (2019) Testosterone or estradiol when implanted in the medial preoptic nucleus trigger short low-amplitude songs in female canaries. eNeuro 6:ENEURO.0502-18.2019.

Vicario DS (1991) Organization of the zebra finch song control system: II. Functional organization of outputs from nucleus Robustus archistriatalis. J Comp Neurol 309:486-494.

Voigt C, Leitner S (2008) Seasonality in song behaviour revisited: seasonal and annual variants and invariants in the song of the domesticated canary (Serinus canaria). Horm Behav 54:373-378. 